\title{
Mediastinal Lymphoma with Complete Atrioventricular Block in a Horse
}

\author{
Akihiko SUGIYAMA $^{1) *}$, Takashi TAKEUCHI ${ }^{1)}$, Takehito MORITA ${ }^{2)}$, Aya MATSUU ${ }^{3)}$, Teppei KANDA ${ }^{3)}$, \\ Akinori SHIMADA ${ }^{2)}$, Tomohiko AMAYA ${ }^{4)}$ and Yoshiaki HIKASA ${ }^{3)}$ \\ ${ }^{1)}$ Departments of Veterinary Laboratory Medicine, ${ }^{2)}$ Veterinary Pathology and ${ }^{3)}$ Veterinary Internal Medicine, School of Veterinary \\ Medicine, Faculty of Agriculture, Tottori University, Minami 4-101 Koyama-cho, Tottori, Tottori 680-8553 and \\ 4)Yamato-Kogen Animal Medical Clinic, Kawaharajo 991 Habikino, Osaka, 583-0867, Japan
}

(Received 24 January 2008/Accepted 20 May 2008)

$\overline{\text { ABSTRACT. A } 15 \text {-year-old, neutered-male pony presented with a history of weight loss during } 4 \text { months. Clinical evaluation revealed }}$ severe bradycardia and complete atrioventricular block. At necropsy, a lobulated mass in the anterior mediastinum and moderate enlargement of the superficial cervical lymph nodes were observed. The vagus nerve and the brachiocephalic trunk were embedded in this anterior mediastinal tumor. Histologically, the mass was composed of sheets of neoplastic lymphoid cells expressing CD3, with a low mitotic rate. To the best of our knowledge, this is the first reported case of mediastinal lymphoma associated with complete atrioventricular block in horses.

KEY WORDS: complete atrioventricular block, equine, mediastinal lymphoma.

J. Vet. Med. Sci. 70(10): 1101-1105, 2008

Lymphoma is the most common neoplasm of the thorax in horses, accounting for $54.2 \%$ of thoracic tumors in 35 horses [28]. Common clinical signs of mediastinal lymphoma in horses include weight loss, inappetence, ventral edema, distended jugular veins, muffled heart sounds, tachycardia, pyrexia and pleural effusion [11, 22, 30, 32]. Other signs that may be detected are peripheral lymphadenopathy, dysphagia, coughing, and dyspnea [11, 21, 30]. These clinical signs in horses with mediastinal lymphoma are attributable to compression of structures in the cranial mediastinum, including the cranial vena cava, vagus nerve, thoracic duct, right lymphatic duct, thoracic part of esophagus, and trachea, by the tumor $[1,8]$. A search of the English literature for the past 20 years revealed no report of equine mediastinal lymphoma with complete atrioventricular (AV) block.

Complete AV block is characterized on an electrocardiogram by the lack of a relationship between the $\mathrm{P}$ waves and the QRS complexes. This occurs as a result of a total failure of the AV condition. The atria and the ventricles beat independently of one another and at their own intrinsic rate, and ventricles are usually much slower than those of the atria [4, 9, 17]. The QRS-T configuration varies and is dependent upon the origin of the ventricular pacemaker tissue $[10,15]$. The clinical signs associated with complete AV block are exercise intolerance, weakness, syncope, or congestive heart failure $[4,9,17]$. The present report describes an unusual case of equine mediastinal lymphoma with complete AV block.

A 15-year-old, neutered-male pony presented with a history of weight loss during 4 months. This case had a history

\footnotetext{
* Correspondence to: Sugiyama, A., Department of Veterinary Laboratory Medicine, School of Veterinary Medicine, Faculty of Agriculture, Tottori University, Minami 4-101 Koyama-cho, Tottori, Tottori 680-8553, Japan.

e-mail: sugiyama@muses.tottori-u.ac.jp
}

of enucleation of the left eye 3 years before admission, because squamous cell carcinoma had occurred in the nictitating membrane of the left eye. At the time of admission to the Tottori University veterinary teaching hospital, the pony was in poor physical condition (200 kg body weight) and depressed. Rectal temperature, heart and respiration rates were $37.4^{\circ} \mathrm{C}, 21$ beats/min and 33 breaths/min, respectively. The heart sounds were muffled. Hematological evaluation revealed mild nonregenerative anemia (Table 1). Biochemical examinations revealed slightly high serum alkaline phosphatase $(745 \mathrm{IU} / l)$, low total protein $(5.8 \mathrm{~g} / \mathrm{d} l)$ and albu$\min (2.0 \mathrm{~g} / \mathrm{d} l)($ Table 1$)$. Serum lactate dehydrogenase (LDH) was within the normal value (292 IU/l), but $\mathrm{LDH}_{4}$ and $\mathrm{LDH}_{5}$ were high (21\% and 8.3\%, respectively). Blood gases and acid-base variable in samples taken from carotid artery and jugular vein were within normal limits (Table 2), indicating minimal respiratory failure. The elevated levels of serum alkaline phosphatase and $\mathrm{LDH}_{5}$ indicated liver damage.

A lead Apex-Base electrocardiogram revealed severe complete atrioventricular block and sometimes premature ventricular contractions. To evaluate the involvement of the vagus nerve in inducing the atrioventricular block, atropine sulfate at $0.03 \mathrm{mg} / \mathrm{kg}$ was injected subcutaneously. Treatment with atropine did not alter the arrhythmia during 30 min after injection. In addition, $0.0125 \mathrm{mg} / \mathrm{kg}$ atropine was further injected intravenously, but this did not prevent the complete atrioventricular block (Fig. 1).

Echocardiographic examination showed extension of the right atrium and right ventricle. The fractional shortening of the left ventricle was $40.9 \%$, within the reference value. The echogenic mass was observed in the anterior to the right atrium at the base of the heart.

The owners desired euthanasia in this case. A complete necropsy was performed after clinical, hematologic, plasma biochemical, electrocardiographic and echocardiographic 
Table 1. Results of haematological and serum biochemical measurements on admission

\begin{tabular}{lclc}
\hline Variable & \multicolumn{1}{c}{ Value } & \multicolumn{1}{c}{ Variable } & \multicolumn{1}{c}{ Value } \\
\hline RBC & $576 \times 10^{4} / \mu l$ & Aspartate amino transferase & $220 \mathrm{IU} / l$ \\
$\mathrm{PCV}$ & $29.5 \%$ & Alkaline phosphatase & $745 \mathrm{IU} / l$ \\
$\mathrm{Hb}$ & $10.9 \mathrm{~g} / \mathrm{d} l$ & Lactic dehydrogenase & $292 \mathrm{IU} / l$ \\
$\mathrm{MCV}$ & $51.2 \mathrm{fl}$ & Blood urea nitrogen & $15.7 \mathrm{mg} / \mathrm{d} l$ \\
$\mathrm{MCH}$ & $18.9 \mathrm{pg}$ & Creatinine & $0.7 \mathrm{mg} / \mathrm{d} l$ \\
$\mathrm{MCHC}$ & $36.9 \mathrm{~g} / \mathrm{d} l$ & Glucose & $111 \mathrm{mg} / \mathrm{d} l$ \\
Platelets & $18.2 \times 10^{4} / \mu l$ & Total cholesterol & $67 \mathrm{mg} / \mathrm{d} l$ \\
WBC & $11500 / \mu l$ & Sodium & $136 \mathrm{mEq} / l$ \\
Eosinophils & $115 / \mu l$ & Potassium & $4.3 \mathrm{mEq} l$ \\
Basophils & $0 / \mu l$ & Chloride & $92 \mathrm{mEq} / l$ \\
Segmented neutrophils & $7935 / \mu l$ & Calcium & $12 \mathrm{mg} / \mathrm{d} l$ \\
Band neutrophils & $0 / \mu l$ & Total protein & $5.8 \mathrm{~g} / \mathrm{d} l$ \\
Lymphocytes & $3450 / \mu l$ & Albumin & $2.0 \mathrm{~g} / \mathrm{d} l$ \\
Monocytes & $0 / \mu l$ & & \\
\hline
\end{tabular}

Table 2. Blood gases and acid-base variables

\begin{tabular}{lcc}
\hline & Arterial blood & Venous blood \\
\hline $\mathrm{pH}($ unit) & 7.41 & 7.39 \\
$\mathrm{P} \mathrm{CO}_{2}(\mathrm{mmHg})$ & 39.5 & 46.3 \\
$\mathrm{P} \mathrm{O}_{2}(\mathrm{mmHg})$ & 88 & 32 \\
$\mathrm{Base} \mathrm{excess}(\mathrm{mmol} / \mathrm{L})_{\mathrm{HCO}_{3}(\mathrm{mmol} / \mathrm{L})}^{1}$ & 3 \\
$\mathrm{~T} \mathrm{CO}_{2}(\mathrm{mmol} / \mathrm{L})$ & 25.3 & 28.1 \\
$\mathrm{~S} \mathrm{O}_{2}(\%)$ & 27 & 29 \\
\hline
\end{tabular}

examinations, and blood gas analyses.

Macroscopical examination showed a lobulated mass (12 $\times 8 \times 6 \mathrm{~cm})$ in the anterior mediastinum and moderate enlargement of the superficial cervical lymph nodes (Fig. 2 (1)). The vagus nerve and the brachiocephalic trunk were embedded in this anterior mediastinal tumor (Fig. 2 (1)).
The cut surface of the mediastinal mass was soft and mottled cream and red in color. In the liver, sclerosis and atrophy of hepatic parenchyma and congestion were observed. In the heart, dilatation of the right ventricle, thinning of the right ventricle wall and hydropericardium were observed. A moderate amount of clear yellow ascites was observed in the peritoneal cavity.

The tissue was fixed in 10\% neutral-buffered formalin and embedded in paraffin wax. Sections were cut at $5 \mu \mathrm{m}$ and stained with hematoxylin and eosin (HE). For immunohistochemistry, anti-human CD3 polyclonal antibody (DakoCytomation, Glostrup, Denmark), anti-human CD79 $\alpha$ monoclonal antibody (clone HM57)(Dako) and anti-human CD20cy monoclonal antibody (Dako) were used as a primary antibody. For CD3, noimmune rabbit serum (Dako) was substituted for the primary antibody;

a.

b.

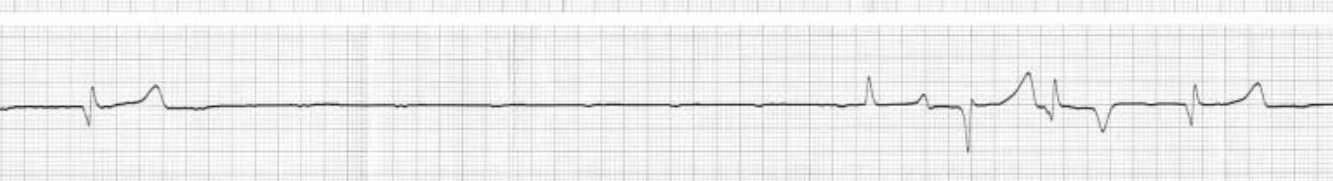

c.

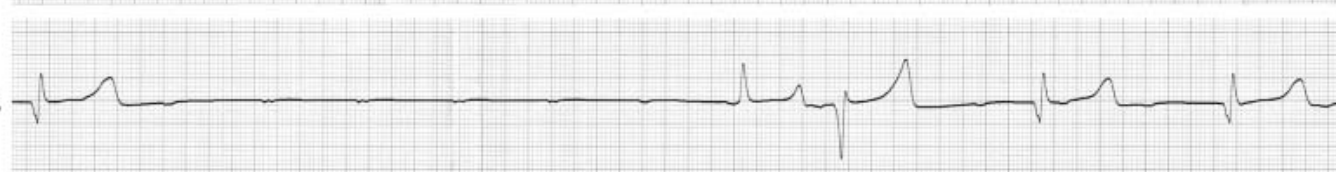

d.

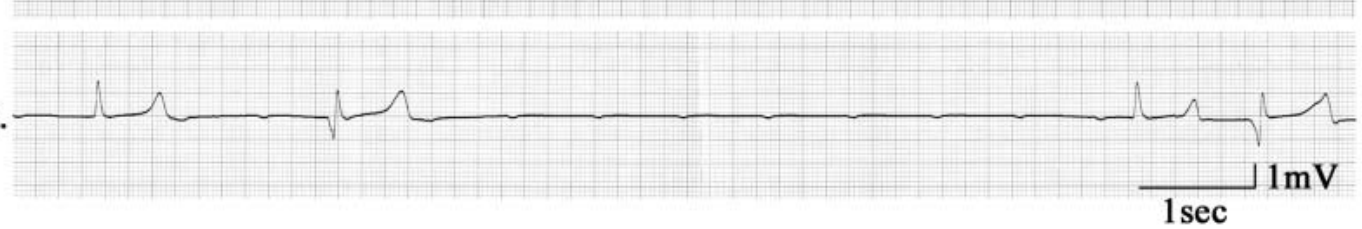

Fig. 1. A lead Apex-Base electrocardiogram. a. Prior to atropine injection. b. $15 \mathrm{~min}$ after subcutaneous injection of atropine. c. $30 \mathrm{~min}$ after subcutaneous injection of atropine. d. $5 \mathrm{~min}$ after intravenous injection of atropine. 

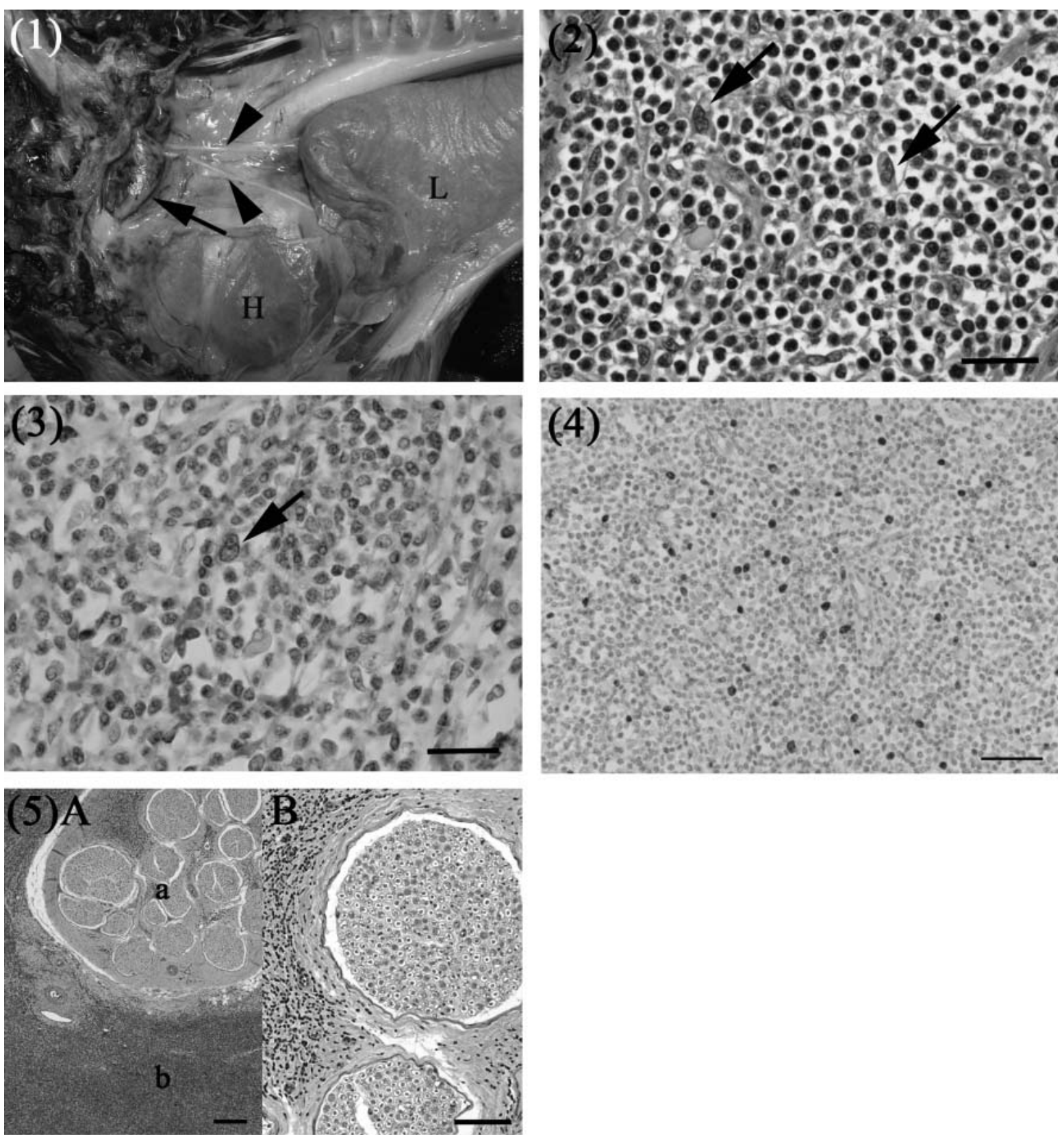

Fig. 2. (1) A mass in the anterior mediastinum (arrow). The vagus nerve (arrowheads) was embedded in this anterior mediastinal tumor. H: Heart; L: Lung. (2) Microscopical features of the anterior mediastinal mass showing diffuse proliferation of the neoplastic lymphoid cells. The neoplastic cells were mainly characterized by small cell size, typically with scant amounts of cytoplasm. The nuclei were mostly round or ovoid and showed dense chromatin. Occasionally, the neoplastic cells showed relatively large cell size with irregular-shaped nuclei (arrow). HE stain. Bar $=30 \mu \mathrm{m}$. (3) Both small-cell- and large-cell-sized (arrow) neoplastic cells were positive for CD3. Immunohistochemistry. Bar $=30 \mu \mathrm{m}$. (4) Scattered neoplastic cells were positive for Ki-67 antigen. Immunohistochemistry. Bar=50 $\mu \mathrm{m}$. (5) Microscopical features of the vagus nerve. HE stain. A: The vagus nerve (a) was surrounded by neoplastic tissue (b). Bar $=300 \mu \mathrm{m}$. B: There was no sign of neoplastic cells infiltration into the nerve tissue. Bar=30 $\mu \mathrm{m}$.

mouse immunoglobulin solution (Mouse IgG1 or IgG2a; Dako) was used as a negative reagent control in all procedures with monoclonal antibodies. For each reagent, a section of an appropriate normal equine tissue sample was used as a positive control. Tissue sections for detection of each antigen were immersed in $0.01 \mathrm{M}$ citrate buffer ( $\mathrm{pH}$ 6.0) and autoclaved for $15 \mathrm{~min}$ at $121^{\circ} \mathrm{C}$ to retrieve antigens. All sections were dewaxed, rehydrated, rinsed with $0.05 \mathrm{M}$ trisbuffered saline containing Tween (TBST; $\mathrm{pH} 7.6$ ), treated with hydrogen peroxide $1 \%$ in distilled water and then 
rinsed again with TBST. Slides were incubated with primary antibody for $30 \mathrm{~min}$ at room temperature. Peroxidaselabeled amino acid polymer (Simple Stain MAX-PO; Nichirei, Tokyo, Japan) secondary antibody systems were used; Slides were incubated with the secondary antibody for $30 \mathrm{~min}$ at room temperature. They were then rinsed with TBST before being treated with a 3,3'-diaminobenzidine solution containing hydrogen peroxide $0.01 \%$ to permit a peroxidase colour reaction. After a further wash with TBST, slides were counterstained with Mayer's hematoxylin.

Histologically, the anterior mediastinal mass consisted of sheets of neoplastic lymphoid cells (HE stain; Fig. 2 (2)). The neoplastic cells were mainly characterized by a small cell size and varied from 3 to $4 \mu \mathrm{m}$ in diameter, typically with scant amounts of cytoplasm. The nuclei were mostly round or ovoid and showed dense chromatin. Occasionally, the neoplastic cells showed large cell size (6 to $11 \mu \mathrm{m}$ in diameter) with irregular-shaped nuclei having irregularly clumped chromatin (Fig. 2 (2) arrows). Mitotic figures were sparse (1.04 \pm 0.52 per 10 high-power fields). The neoplastic cells expressed CD3 (Fig. 2 (3)), but did not label for CD79 $\alpha$ and CD20cy. The proliferation index, measured as the percentage of Ki-67-positive cells in high-power fields (a total of approximately 1000 cells), was 12\% (Fig. 2 (4)). The neoplastic cells reached the perineurium of the vagus nerve, but did not infiltrate in the nerve tissue (Fig. 2 (5)). There were no neoplastic lesions in the cardiac conduction system or the cardiac muscle tissue. No neoplastic cells were observed in the ascites of the peritoneal cavity. In the superficial cervical lymph nodes, lymphatic sinuses were filled with neoplastic cells. Follicular centres were sometimes replaced by neoplastic cells. Centrilobular congestion and pseudolobules separated by collagen bundles in addition to periportal (including portal tract) fibrosis were observed in the liver.

The present case was classified as diffuse small lymphocytic lymphoma, according to the Working Formation [26]. When 81 horses with lymphoma were classified according to the Working Formation, 1.2\% had diffuse small lymphocytic type [16]. Diffuse small lymphocytic lymphoma is categorized into low grade malignancy in human and animals $[16,26]$. In human non-Hogkin's lymphomas, the percentage of Ki-67 positive cells (Ki-67 index) appears to be correlated with the grades of malignancy [12], and to constitute an independent prognostic factor within the different groups. This extends the possibilities of prognosis for individual cases $[13,14,23]$. In canine non-Hogkin's lymphomas, a highly significant correlation was established between the proportion of $\mathrm{Ki}-67$ positive cells and the classification into low-grade (Ki-67 index <21\%) and highgrade malignancy (Ki-67 index $>21 \%$ and usually $>29 \%$ ) [7]. The present case was categorized into low-grade malignancy from the morphologic characteristics, and the Ki-67 index of the present case was $12 \%$, which is consistent with a previous canine study [7].

The prognosis for survival of horses with mediastinal lymphoma is reportedly poor [10, 15, 24, 25]. Reports of successful treatment for this disease were not found, and death usually occurs within several months after clinical signs develop [21, 28, 30, 31]. Involvement of other organs, such as abdominal lymph nodes, kidneys, spleen, and liver, is commonly observed in horses with mediastinal lymphoma $[11,21,28,30,31]$. In the present case, there were no metastatic lesions in abdominal organs, and it showed relatively rare lesion distribution.

In human patients, the anatomical basis of complete AV block has been the subject of considerable study. Permanent complete AV block is almost always due to a direct effect of pathological processes on the cardiac conduction system or an extension of pathological processes from surrounding areas $[18,19]$. These processes include neoplastic disease, myocarditis, infectious endocarditis, ischemic coronary disease, fatty infiltration, uremia, and hemochromatosis $[2,3$, $18,19]$. The most common cause of this type of block in elderly human patients is sclerosis of the left side of the cardiac skeleton $[18,19]$. In domestic animals, complete AV block is associated with heart disease, especially myocardial disorders, that include congenital heart defects, infiltrative cardiomyopathy (amyloidosis or neoplasia), idiopathic fibrosis, myocardial infarction, hypertrophic cardiomyopathy, bacterial endocarditis, myocarditis associated with Lyme disease, and Chagas' disease [4, 9, 17, 20].

In lymphomas associated with complete atrioventricular block reported in human, the neoplastic lesions occurred in the cardiac conduction system in all the affected cases to our knowledge [5, 6, 22, 24, 25, 27, 29]. Because there were no lesions in the cardiac conduction system, possibly the complete atrioventricular block was attributable to compression of structures of the vagus nerve in the present case. However, in the present case, atropine treatment did not alter the complete AV block. Although the reason for this event is unknown, the dosage of atropine might not have been enough to block the stimulation of the vagus nerve due to the lymphoma.

The hepatic congestion and fibrosis in the present case seem attributable to chronic right-side heart failure occurring primarily or secondarily after chronic left-side heart failure induced by complete AV block [32]. The emaciation, ascites and hypoalbuminemia occurred secondarily after these hepatic injuries.

To the best of our knowledge, there have been no reports of equine mediastinal lymphoma with complete AV block. Although the actual pathogenic mechanism remains unclear, we considered it valuable to describe such a rare case.

\section{REFERENCES}

1. Beadle, R. E. 1991. Disease of the pleura, mediastium, diaphragm and thoracic wall. pp. 458-459. In: Equine Medicine and Surgery, 4th ed., vol. 1. (Colahan, P. T., Mayhew, I. G,. Merritt, A. M. and Moore, J. N. eds.), American Veterinary Publications, Inc., California.

2. Bharati, S. 2001. Pathology of the conduction system. pp. $607-$ 628. In: Cardiovascular Pathology, 3rd ed. (Silver, M. D., Got- 
lieb, A. I. and Schoen, F. J. eds.), Churchill Livingstone, New York.

3. Bharati, S. and Lev, M. 1984. Pathology of atrioventricular block. Cardiol. Clin. 2: 741-751.

4. Carr, A. P., Tilley, L. P. and Miller, M. S. 2001. Treatment of cardiac arrhythmias and conduction disturbances. pp. 371-405. In: Manual of Canine and Feline Cardiology, 3rd ed. (Tilly, L. P. and Goodwin, J. K. eds.), W. B. Saunders, Philadelphia.

5. Clifford, S. M., Guerra, S. M. and Mangion, J. R. 2003. Massive metastatic intracardiac lymphoma presenting with complete heart block with resolution following chemotherapy. Echocardiography 20: 201-202.

6. Engelen, M. A., Juergens, K. U., Breithardt, G. and Eckardt, L. 2005. Interatrial conduction delay and atrioventricular block due to primary cardiac lymphoma. J. Cardiovasc. Electrophysiol. 16: 926.

7. Forrester, S. D., Troy, G. C. and Fossum, T. W. 1988. Pleural effusions: pathophysiology and diagnostic considerations. Compend. Contin. Educ. Pract. Vet. 10: S121-S136.

8. Fournel-Fleury, C., Magnol, J. P., Chabanne, L., Ghernati, I., Marchal, T., Bonnefond, C., Bryon, P. A. and Felman, P. 1997. Growth fractions in canine non-Hodgkin's lymphomas as determined in situ by the expression of the Ki-67 antigen. $J$. Comp. Pathol. 117: 61-72.

9. Fox, P. R. and Harpster, N. K. 1999. Diagnosis and management of feline arrhythmias. pp. 386-399. In: Text of Canine and Feline Cardiology, 2nd ed. (Fox, P. R., Sisson, D and Moise, N. S. eds.), W. B. Saunders, Philadelphia.

10. Fox, P. R., Moise, N. S., Woodfield, J. and Darke, P. G. G. 1991. Techniques and complications of pacemarker implantation in four cats. J. Am. Med. Assoc. 199: 1742-1753.

11. Genetzky, R. M., Ducor, D. M., Hagemoser, W. A. and Van Der Maaten, M. J. 1982. Mediastinal lymphosarcoma in a gelding. Mod. Vet. Pract. 12: 972-977.

12. Gerdes, J., Dallenbach, F. and Lennert, K. 1984. Growth fractions in malignant non-Hodgkin's lymphomas (NHL) as determined in situ with the monoclonal antibody Ki-67. Hematol. Oncol. 2: 365-371.

13. Grogan, T. M., Lippman, S. M., Spier, C. M., Slymen, D. J., Rybski, J. A., Rangel, C.S., Ricter, L. C. and Miller, T. P. 1988. Independent prognostic significance of a nuclear proliferation antigen in diffuse large cell lymphomas as determined by the monoclonal antibody Ki-67. Blood 71: 1157-1160.

14. Hall, P. A., Richard, M. A., Gregory, W. M., d'Ardenne, A. J., Lister, T. A. and Stansfield, A. G. 1988. The prognostic value of Ki-67 immunostaining in non-Hodgkin's lymphoma. $J$. Pathol. 154: 223-235.

15. Harpster, N. K. 1977. Cardiovascular diseases of the domestic cat. Adv. Vet. Sci. Comp. Med. 21: 39-74.

16. Jacobs, R. M., Messick, J. B. and Valli, V. E. 2002. Tumors of the hemolymphatic system. pp. 119-198. In: Tumors of Domestic Animals (Meuten, D. J. ed.), Iowa State Press, Iowa.

17. Kittleson, M. D. 1998. Diagnosis and treatment of arrhythmias (dysrhythmias). pp. 449-494. In: Small Animal Cardiovascular Madicine (Kittleson, M. D. and Kienle, R. D. eds.), Mosby, St. Louis.
18. Lev, M. 1964. Anatomic basis for atrioventricular block. Ann. New York Acad. Sci. 111: 817-829.

19. Lev, M. and Bharati, S. 1975. Atrioventricular and intraventricular conduction disease. Arch. Intern. Med. 135: 405-410.

20. Machida, N., Katsuda, S., Kobayashi, Y. and Mitsumori, K. 2005. A histological study of the cardiac conduction system in a Heifer with complete atrioventricular block. J. Comp. Pathol. 133: $68-72$.

21. Mair, T. S. and Brown, P. J. 1993. Clinical and pathological features of thoracic neoplasia in the horse. Equine Vet. J. 25: 220-223.

22. Matsuo, T., Nishiura, R., Tsumori, Y., Maeno, M., Kumagae, H., Imamura, T., Koiwaya, Y., Eto, T., Nagamine, H. and Inoue, S. 1999. Disappearance of complete atrioventricular block after chemotherapy for malignant lymphoma: a case report. J. Cardiol. 34: 345-349.

23. Miller, T. P., Grogan, T. M., Dahlberg, S., Spier, C. M., Braziel, R. M., Banks, P. M., Foucar, K., Kjeldsberg, C. R., Levy, N., Nathwani, B. N., Schnitzer, B., Tubbs, R.R., Gaynor, E. R. and Fisher, R. I. 1994. Prognostic significance of the Ki-67associated proliferative antigen in aggressive non-Hodgkin's lymphomas: a prospective Southwest Oncology Group trial. Blood 83: 1460-1466.

24. Montiel, V., Maziers, N. and Dereme, T. 2007. Primary cardiac lymphoma and complete atrio-ventricular block: case report and review of the literature. Acta. Cardiol. 62: 55-58.

25. Nakayama, Y., Uchimoto, S., Tsumura, K. and Morii, H. 1997. Primary cardiac lymphoma with infiltration of the atrioventricular node: remission with reversal of the atrioventricular block induced by chemotherapy. Cardiology 88: 613-616.

26. National Cancer Institute. 1982. The non-Hodgkin's lymphoma pathologic classification project: National Cancer Institute sponsored study of classifications of non-Hodgkin's lymphomas. Summary and description of a working formulation for clinical usage. Cancer 49: 2112-2135.

27. Shigenobu, M., Mukuzono, H. and Teramoto, S. 1988. A case of complete atrioventricular block due to malignant lymphoma. Acta Med. Okayama 42: 355-358.

28. Sweeney, C. R. and Gillette, D.M. 1989. Thoracic neoplasm in equids: 35 cases. J. Am. Vet. Med. Assoc. 195: 374-377.

29. Tail, C. J., Wang, W. S., Chung, M. T., Liu, J. H., Chiang, C. Y., Yen, C. C., Fan, F. S., Chiou, T. J. and Chen, P. M. 2001. Complete atrio-ventricular block as a major clinical presentation of the primary cardiac lymphoma: a case report. Jpn. J. Clin. Oncol. 31: 217-220.

30. Thatcher, C.D., Roussel, A. J., Chickering, W. R. and Saunders, G. K. 1985. Pleural effusion with thoracic lymphosarcoma in a mare. Compend. Contin. Educ. Pract. Vet. 7: S726S730.

31. Van den Hoven, R. and Franken, P. 1983. Clinical aspects of lymphosarcoma in the horse: a clinical report of 16 cases. Equine Vet. J. 15: 49-53.

32. Van Vleet, J. N. and Ferrans, V. J. 2001. Cardiovascular system. pp. 197-233. In: Thomson's Special Veterinary Pathology, 3rd ed. (McGavin, M. D., Carlton, W. W. and Zachary, J. F. eds.), Mosby, St. Louis. 